\title{
CUERPO Y OTREDAD EN LA POESÍA DE GIRONDO
}

Para hablar de vanguardias en América Latina convendría despojarse del afán clasificador, por respeto a la esencia ruptural de esa estética de los años veinte. Hay, sin embargo, una ya larga tradición crítica desde entonces, y en ella se ha recurrido a cuestiones históricas que determinan momentos, y a razones genealógicas que generaron como troncos familiares entre grupos de poetas.

Sin ánimo de adherir muy estrechamente a ninguna postura crítica, en particular, consideramos válido el planteo de la existencia de momentos en el desarrollo de las vanguardias. Es claro que cada tramo de ese corte cronológico que abarcan los ciclos vanguardistas responde a la impronta de una escritura que emerge como líder, así se reconoce a Vicente Huidobro como el inaugurador de una sucesión que habrá de culminar con Trilce de César Vallejo. Ocurre que simultáneamente se produce la explosión del fenómeno de las revistas literarias, cuya prédica programática pone en contacto los "ismos" europeos con la actitud iconoclasta de la poesía hispanoamericana.

De esa onda expansiva estrenada en 1918 con Poemas árticos de Huidobro, el movimiento se robustece en nombres y efectos que no siempre incluyen los mismos protagonistas. Es interesante observar que cuando el examen crítico cambia de perspectiva se priorizan nombres paradigmáticos y se desconocen otros, según el punto de arranque del relevamiento historiográfico. Fernando Alegría ${ }^{1}$ y Octavio $\mathrm{Paz}^{2}$, por ejemplo, omiten el nombre de Girondo entre los representantes significativos de la vanguardia hispanoamericana, pero es sabido que el ensayo de Paz es rapsódico más que analítico. La crítica argentina, en cambio, no sólo abrió un espacio para Girondo, sino que lo coloca entre los modelos canónicos de vanguardia, es el caso de Saúl Yurkievich (1984 a : 16) quien define como textos decisivos la progresión que va de Altazor (1919) a En la masmédula en 1954, pasando por el Vallejo de Trilce (1923) y el Neruda de Residencia en la tierra (1935).

Las precisiones temporales importan sólo a la hora de reconocer que, si bien los años veinte sirven de despegue, las décadas posteriores propician el ahondamiento del encuadre vanguardista de nuestro Oliverio.

1 En un trabajo de 1971 -año de edición- el escritor chileno sitúa en la vanguardia lírica hispanoamericana a Macedonio Fernández, a Borges y a César Fernández Moreno, y aún a expresiones posteriores como Noé Jitrik y Spunberg, pero no nombra a Girondo.

2 Octavio Paz tiene muchos ensayos dedicados a la poesía hispanoamericana, en la mayoría de los casos, muy abarcadores y, por tanto muy generales. Consideramos aquí un artículo édito en "El signo y el garabato" (1986) en el que reconoce como vanguardistas argentinos a Albero Girri, Enrique Molina, después de Borges, pero tampoco asoma Girondo. Omisión que reitera en "Los nuevos acólitos" (1983:95) 
Sin desconocer que los rasgos de la escritura de vanguardia no se agotan en ningún listado que apunte a la descripción de lo experimental, ni en el registro de lo contestatario, nos centraremos en un aspecto inherente a la tendencia vanguardista, en general, pero que en Girondo cobra una semanticidad particular. Se trata de la incógnita de la identidad del yo de la enunciación, en el caso de esta lírica que todo lo subvierte por ser proclive a la configuración de la parodia por la búsqueda del contraste entre la carcajada y la actitud metafísica.

$\mathrm{Si}$ atendemos a especulaciones teóricas respecto de la figura autoral que construye el sujeto lírico en la poesía de vanguardia, una difundida postura de Hamburger (1986) sostiene que la identidad es una y la misma, a diferencia de ese fenómeno en la ficción narrativa.

Este presupuesto trae aparejado un problema cuando se intenta trasladarlo a la producción de Girondo, pues su andadura lírica, precisamente por su enclave vanguardista, contiene una etapa en que el autor desdice del verso para acogerse a un tipo de prosa poética colindante con alguna variable narrativa. Hablamos de Espantapájaros (1932), texto cuya pertenencia al género lírico se defiende por el caligrama inicial, tan emblemático de la vanguardia como intencionado en la apertura del poemario. ${ }^{3}$ Con excepción de este poema-signo visual, mitad juego, mitad declaración paródica, y del número doce de indudable factura versificada y rítmica, las veintitrés unidades de la macroestructura se perciben como relatos fictivos o soliloquios desde una entidad gramatical reconocible.

La afirmación precedente parte de contrastar el modo enunciativo de los libros de la primera etapa con la escritura posterior; tanto en Veinte poemas para ser leídos en el tranvía como en Calcomanias es frecuente la ocurrencia de construcciones impersonales como si, realmente, quien percibiese las estampas de viaje fuese una cámara, o simplemente las cosas transcurriesen sin un efecto subjetivo asumido: "Hay quioscos", "A veces

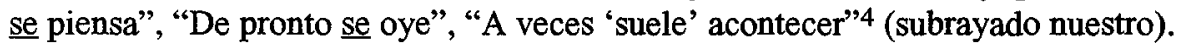

Si bien en la producción temprana la espacialidad está determinada por el itinerario de viaje, y el paratexto indica el anclaje temporal, el discurso simula la errancia de la mirada desde una imprecisión que habrá de evolucionar en un registro pronominal más categórico.

El problema presentado más arriba está en la confluencia del fenómeno de la asunción del sujeto discursivo con un tipo de poesía más próxima a la narrativa que a la lírica. Tal como afirma la teoría de Hamburger ${ }^{5}$, en Girondo-Espantapájaros hay casos en

3 Es inevitable recordar "Custodia", caligrama de Octavio Paz perteneciente a Salamandra (1962), sin desatender al hecho de que la poesía como signo visual tiene sus antecedentes en el surrealismo francés, que a su vez lo hereda de una larga tradición.

4 Las citas corresponeden a "Croquis en la arena", "Nocturno", "Milonga", respectivamente, textos escritos hasta 1922.

5 Concretamente la estudiosa afirma “... el sujeto de la lírica se identifica con el poeta de la misma manera que lo hace el sujeto enunciante de una obra historiográfica...". 
que la enunciación, desde la perspectiva del YO, responde al estatuto de la ficción, por el análogo metafórico al que acude:

Mi digestión inventa una cantidad de crustáceos que se entretienen en perforarme el intestino. [...] y es rarísimo que pueda sonarme la nariz sin encontrar en el pañuelo un cadáver de cucaracha. [...]

(Espantapájaros, 6)

Sin embargo el Espantapájaros número 4 construye a partir del YO la figura del poeta, desde un raconto autorreferencial — por los juegos verbales y rupturas lógicas- va perfilando la poética girondina, así es que

Abandoné las carambolas por el calambur [...] Preferí el sublimado a lo sublime [...] Mi repulsión hacia los parentescos, me hizo eludir los padrinazgos, a los padrenuestros [...]

El texto 10 opera como concomitante de los ejemplos citados, la estructura diegética determina un antes y un después que remiten al intratexto tanto en lo biográfico referencial como en lo literario:
Aunque ya han transcurrido muchos años, lo recuerdo
perfectamente [...] cuando un tranvía me susurró al pasar: En la vida hay que sublimarlo todo... no hay que dejar nada sin sublimar!
[...]
Desde entonces la vida tiene un significado distinto para mí. Lo que antes me resultaba grotesco o deleznable, ahora me parece sublime.

(el subrayado es nuestro)

La alusión al tranvía, obviamente, puede estar remitiendo a su iniciación vanguardista, tiempo en que el YO autoral optó por la ruptura del logos, por la irreverencia, el erotismo a veces lúdico, a veces escatológico, y la risa en todas sus gamas del sainete a lo trágico. Todos ellos, signos surrealistas condensados en el tono paródico de algunos baluartes del psicoanálisis como el "sublimar", retomado en otros textos contemporáneos o posteriores.

Para desembocar en conclusiones respecto de la imagen textual del poeta construida por el enunciado, tenemos previsto avanzar analizando un corpus que incluya En la masmédula, esto es, hacernos cargo de los antecedentes críticos que sostienen la evolución de un "nosotros difuso" de los libros de viaje a "un yo nítidamente asumido" de Espantapájaros (Al alcance de todos) (Thenon, 1968:86-87), pero también es indagar qué trasuntan esas mutaciones.

Aún en el terreno de la prosa-poesía el texto No 8 apunta nuevamente claves para la configuración de la identidad entre sujeto autoral y enunciado. Hablamos del yo escindido 
en múltiples personalidades, tópico frecuentado por poetas de la talla de Machado $^{6} \mathrm{o}$ de Octavio $\mathrm{Paz}^{7}$, con la diferencia que aquí la reflexión se regocija en la parodia. ${ }^{8}$

Acaso esa dualidad sea el anticipo de lo que vehiculiza el juego pronominal en los poemarios posteriores. Enrique Molina ha observado que el tránsito de una etapa a otra en la producción de $O$. Girondo radica en el desplazamiento de "un universo físico a un universo moral" y ese "paso de la geografia a la ética" (1962:28) lo marca Persuasión de los días (1942). De ese poemario fundamental en la evolución girondina hacia su "médula" lírica, responden a nuestro interés la serie de los nocturnos que constituyen un corpus numerado. 9 Irrumpe aquí la presentificación de lo corporeo como signo de identidad. El ser se enajena del YO y se dice a través de todas las formas de la carnadura: "mano", "venas", "huesos", "tendones", "nervios", "sangre", "nuca", "esqueleto", "arterias".

Entre el primer nocturno y uno de los Embelecos - sección también constitutiva del libro que nos ocupa - se advierte cohesión, a pesar de la distancia entre uno y otro. La recurrencia de "No soy Yo quien..." parece resolverse en "Dicotomía incruenta" que sintetiza algo de la visión lúdica de la etapa temprana con el filo trágico de este ser que duda de su propia existencia.

Cuando voy a sentarme
advierto que mi cuerpo
se sienta en otro cuerpo
$\quad$ /que acaba de sentarse

adonde yo me siento.

(Dicotomía incruenta)

Pero la esencia isotópica de los Nocturnos pasa por la tragicidad de la vigilia que todo lo oscurece de orfandad y desasosiego. Es en este cuerpo poemático que el cuerpo se arroga la identidad anaforizada desde el posesivo de primera persona: "Mi mano que se agranda / [...] desmesurada, / enorme, / adherida al insomnio," (Nocturno, 2).

El sistema pronominal de los nocturnos casi elimina el Yo y el enunciador se corporiza, literalmente, por reiteración del posesivo MI unido a los significantes anatómicos: "mis huesos", "mi pulso", "mis nervios", "mi sangre". El deíctico aquí, tan

6 "Converso con el hombre / que siempre va conmigo" dice A. Machado y es conocida su poética de la otredad desarrollada a través de sus personajes apócrifos Juan de Mairena y Abel Martín.

7 Cfr. El arco y la lira.

8 Vale la pena citar un texto ilustrativo: "Yo no tengo una personalidad; soy un cocktail, un conglomerado, una manifestación de personalidades. [...] quisiera obligarlas a que se oculten en los repliegues más ocultos de mi cerebro" (Espantapájaros, 8).

9 Persuasión de los días es un libro de estructura nada simétrica: se compone de tres cuerpos numerados correlativamente, sin embargo el cuerpo 1 alberga una sección de Nocturnos, numerados, a su vez, de 1 a 9 . La parte 2 contiene los embelecos que son trece y llevan títulos. La parte 3, en cambio, se conforma con once poemas, con lo cual rompe la proporción - Parte 1: veintiún poemas, Parte 2: veintidós poemas y Parte 3: once poemas. 
hipostasiado con el sujeto de la enunciación, semantiza indistintamente lugar o existencia en crisis:

\author{
Y tú también \\ quejido, \\ [...] \\ adentro de mis venas, \\ [...] aquí, \\ adentro de lo hueco \\ donde estoy confinado \\ relucido entre tendones,
}

(Nocturno, 4)

El campo semántico de lo corporal-fisiológico, en este corte sincrónico de la producción, remite a agonía exsistencial, a conciencia de la muerte, contrariamente a la connotación vitalista y descralizadora que reviste en los textos de la primera época. ${ }^{10}$ Así, "quejido inútil", / soledad / "sombras", "insomnio", "silencio", "vigilia estéril", "aguas de silencio / de calma, / de misterio /" constituyen un universo discursivo que convive con una presencia enunciadora dramáticamente recluida "entre tendones" o sin ganas de quedarme con el mismo esqueleto (Nocturno, 9).

De acuerdo a esto se podria afirmar que la cadena significante trasunta un sujeto ensimismado en dolor existencial y en cuerpo como cárcel del ser.

De esta dimensión la escritura girondina transita a un nuevo modo de instalar la vacuidad semántica de la pronominalidad, si rescatamos el objetivo de identificar el rol social del poeta, a través de la imagen textual. Tanto en "Arborescencia" como en "Restringido propósito" se lee el preanuncio de una metamorfosis, la figuración de brotar en árbol se concatena con esa suerte de arte poética declarada en "Demasiado corpóreo [...] Tendré que abrir los poros / y disgregarme un poco".

Tal vez el disgregarse se concreta en el procedimiento de descomposición y reengendramiento lingüístico, característico de En la masmédula (1956), cuyo sistema pronominal se estrella en la pluralidad de perspectiva. W. Mignolo (1984:65) se refiere a este fenómeno como "disonancia en la categoría de la persona" y lo explica como un procedimiento común a las textualidades de vanguardia.

Un ejemplo propicio de esta variable es el caso de la doble realización del sujeto: como actor del verbo en primera persona y como objeto de la misma inflexión;

10 No podemos omitir el dato de que existen trabajos que abordan este aspecto desde la teoría bajtiniana, concretamente "las imágenes grotescas del cuerpo y del mundo". Coincidimos con Verónica Seguí en que la textualidad de Girondo es posible de ser leída con ese instrumento teórico. 


Sigo
sólo
me sigo
y en otro absorto otro beodo lodo baldío
$[\ldots]$
me persigo
$[\ldots]$
me persigo
$[\ldots . .$.$] sin estar ya conmigo ni ser un otro otro.$

(Aridandantemente)

Al tratar Espantapájaros detectábamos ya esa tendencia al desdoblamiento en otro (Cfr. pg. 4), esto que parece ser un juego verbal hecho de paronomasia, calambur y aliteración, anticipa su semanticidad en el título que conjuga tres elementos léxicos (adjetivo + adjetivo-adverbio) en un neomodo adverbial. La secuencia de "Sigo / sólo / [...] me persigo / ... / entre fugaces muertes sin memoria / [...] de un extremo a otro estero /" desemboca en "aridandantemente", multilexema que reproduce el título. 11

En actitud metacrítica del análisis que Mignolo hace de los poemas paradigmáticos de la aludida disonancia, consideramos que los textos "Tantanyo" y "Yolleo", ambos ínsitos en la última aventura girondina, no "volatilizan" la figura del poeta por preponderancia de la objetivación del sujeto. Muy por el contrario, este artificio verbo-lúdico permite retrotraer momentos creativos anteriores como "Cansancio" o "Restringido propósito" en donde el yo poético se reconoce: "Cansado, / [...] de este frío esqueleto, /" o, por ejemplo, "Cansado, / sobre todo, / de estar siempre conmigo./"; o cuando reflexiona: "Demasiado corpóreo, / limitado, / compacto./"

Precisamente "Yolleo" aparece como la antonomasia de ese tantanyo de la imagen del poeta, sujeto ajeno a la convención y a la certeza de ser, sujeto vacío a fuerza de verbo, de búsqueda, de juego suicida.

Tal vez la interpretación pueda buscarse en la actitud de los sujetos vanguradistas respecto de la materia, en este caso verbal; el artista de vanguardia sólo ve un signo vacío, aislado de la totalidad. Esa fragmentación es el origen del armado de nuevos sentidos, pero la búsqueda, a veces, es desesperada "porque implica la conciencia de que la realidad se escapa como algo que está en continua formación." (Bürger, 1987 : 134).

Todo esto se traduce en impotencia por la pérdida de posibilidades prácticas de acción transformadora, en términos de realidad social. Yurkievich observa a propósito del "yolleo":

11 Adviértase que un análisis semántico más riguroso arrojaría mayores resonancias. El adjetivo "andante" flanqueado por "árido" y por el sufijo modal sugiere mucho, desde el punto de vista intertextual. Aquel paradigma adjetivado con andante, lo fue no por caballero, sino por sus locuras, ergo este sujeto anda por caminos sin destino e inútilmente porque lo árido no da frutos, no conduce a ninguna parte: El poema está cargado del mismo sentido "baldíos", "neuroyertos", "opios", etc. 
Girondo propone contravenir ese yo egoísta y menguado, lívido, semiausente; preconiza el saneamiento mental por extirpación del "yo antropoco", solitario y mínimo, el menosprecio de ese pasajero espejismo sin mañana. 12

Es así como concluimos que la imagen del poeta en la producción que revisamos, sólo parcialmente- más que la configuración de un sujeto manifiesto, instala un "sujetado" a la autoridad de formaciones culturales. Y en esa ilusoria rebeldía de lo formal reside un buen fermento del decir paródico, ámbito discursivo de una verdad a medias.

\section{Bibliografia}

Alegría, Fernando, "La antipoesía" en: Literatura y revolución. México, F.C.E., 1971. Bürger, Peter, Teoría de la vanguardia. Barcelona, Península, 1987.

Girondo, Oliverio, Obra. Buenos Aires, Losada (5a edición), 1993. Hamburger, Kate, Logique des genres littéraires. Paris, Du seuil, 1986.

Mignolo, W., "La figura del poeta en la lírica de vanguardia". (V. Huidobro, O. Girondo, O. Paz) en: Textos, modelos y metáforas. Xalapa, Universidad de Veracruz, 1984.

Molina, Enrique, "Hacia el fuego central o la poesía de Oliverio Girondo" en: Obra. Op. cit.

\section{Paz, Octavio}

"Los nuevos acólitos" en: La búsqueda del comienzo. Madrid, Fundamentos,1983. “Poesía Latinoamericana" en: El signo y el garabato. México, J. Mortiz, 1986. El arco y la lira. México, F.C.E., 1981.

Rivero, Ma Cristina, "Los años veinte: enunciación y circulación de los discursos literarios en la construcción del imaginario social" en: Actas del VI Congreso Nacional de Literatura Argentina. Córdoba, Universidad Nacional de Córdoba, 1991.

Seguí, Verónica, "El columpio grotesco" en: Espantapájaros (al alcance de todos) de Oliverio Girondo. México, Sexto Encuentro Internacional Mijail Bajtin. en prensa.

Sucre, Guillermo, “Adicciones, adhesiones” en: La máscara, la transparencia. Ensayos sobre poesía hispanoamericana, México, F.C.E., 1985, pp. 235-245.

12 Hace falta aclarar que, pese a esta observación, el crítico desarrolla en "La pupila del cero" un análisis exhaustivo de un corpus mayor al nuestro y sus conclusiones son otras. La diferencia está, tal vez, en un enfoque más filosófico que el nuestro. La circunscripción a lo pronominal tiene que ver con una cuestión de coherencia en un trabajo breve, pero aceptamos que las lecturas pueden ser múltiples. 
Thenon, Susana, "Oliverio Girondo: una historia del fervor" en : «Sun» no 315/1968, Buenos Aires. pp. 82-87.

Stratta, I. y G. Speranza, "Girondo y González Tuñón: el vértigo de los viajes y la evolución" en: Historia de la literatura argentina. Dir. por David Viñas, Buenos Aires, Contrapunto, 1989, pp. 184-209.

Yurkievich, Saúl

-"El relato limítrofe" y "Sobre vanguardias literarias y otras concomitancias" en: A través de la trama. Barcelona, Muchnik, 1984, pp. 74-82 y pp. 7-28.

- "La pupila del cero" en: Fundadores de la poesía Hispanoamericana. Madrid, Ariel, 1984, pp. 149-167.

\section{Povzetek}

\section{TELO IN DRUGOST V GIRONDOVI POEZIJI}

Amelia Royo umešča argentinskega pesnika Oliveria Gironda (1891-1967) v gibanje avantgardne poezije v Latinski Ameriki, čeprav ga nekateri literarni kritiki ne omenjajo, ko govorijo o tem obdobju. Girondo je pravi predstavnik avantgarde tako glede na tematiko in vrsto poezije (avtorica analizira nekaj najbolj značilnih del) kot tudi zgodovinsko, saj je s svojim delom vseskozi prisoten $\mathrm{v}$ gibanju. $\mathrm{V}$ članku so poudarjene nekatere posebnosti Girondove poezije: kontrast med obešenjaškim smehom in metafizičnim iskanjem, razcepitev jaza v več osebnosti, prisotnost parodije. 